\title{
EDITORIAL: THE ART OF THE STRING MULTIPHONIC
}

\author{
Christopher Fox and Ellen Fallowfield
}

Regular readers of TEMPO will recognise that this issue is unusual. All the articles focus on recent research on string multiphonics and span theory, analysis and practice from both the performer and composer's perspective. Ellen Fallowfield has drawn all this material together and most of the words that follow in this editorial are hers, but I want to begin by thanking her for being such a generous and conscientious collaborator. We are both convinced of the value of assembling such a body of work, creating not only a network of information but also models on which to build future developments. In particular we believe that it is important to encourage the assimilation of existing research, particularly across approaches and disciplines, something that is often not pursued sufficiently rigorously in performance practice research.

The theory for predicting the pitch content of string multiphonics is applicable to all stringed instruments, whether they are bowed, plucked or struck. There are some differences in limits according to the properties of the strings and bowing/plucking/striking conditions, but these seem to have less influence than the varying tubes, cones and keys within classes of woodwind instruments which can make pitch content unpredictable, and fingering charts inconsistent. It is curious then that woodwind multiphonics have become much better established in musical practice than string multiphonics. Extensive fingering charts exist for most woodwind instruments and multiphonics are a standard part of woodwind repertoire, taught at conservatoires and used with confidence by composers.

One reason for this is surely the work of Bruno Bartolozzi, whose New Sounds for Woodwind (1967) established a new technical approach. His categorisation of multiphonics into cleanly presented fingering charts (although these have needed significant updates in the intervening decades) provided a basis upon which performers and composers could experiment. He also blazed an ideological trail: 'How is it', he asked, 'that, until today, possibilities which have so long existed, have been always ignored? How is it that instrumental techniques have become fixed in a pattern which does not allow any results except those in conventional use?' ${ }^{1}$ Bartolozzi's book, in combination with John Coltrane's early use of multiphonics on tracks such as 'Harmonique', inspired Arthur Benade's eventual acoustical explanation for the technique, ${ }^{3}$ which provided solid scientific ground. There followed key resources for flute, oboe, clarinet, saxophone

${ }^{1}$ Bruno Bartolozzi, New Sounds for Woodwind, trans. Reginald Smith Brindle (London: Oxford University Press, 1967), p. 3.

2 John Coltrane, 'Harmonique' (1959), released on Coltrane Jazz (CBS, 1961).

3 Arthur H. Benade, Fundamentals of Musical Acoustics, 2nd edition (New York: Dover, 1990), pp. 559-67 (originally published in 1976 by Oxford University Press). 
and bassoon, ${ }^{4}$ and several websites are still refining the model and introducing new multiphonic sonorities, for example, those by Heather Roche and Helen Bledsoe. ${ }^{5}$

Just as woodwind multiphonics emerged from Coltrane's early experimentation on the saxophone, so string multiphonics also seem to have origins in improvisation. Hakon Thelin found photographic evidence of the double bassist Fernando Grillo clearly playing multiphonics in the 1970s (since the first notated scores date from the 1980 s, it is probable that he was improvising). ${ }^{6}$ Guitarist John Schneider produced the first string multiphonic fingering charts in $1985^{7}$ and, when asked about his influences, cited Bartolozzi and work with Horatio Radulescu ${ }^{8}$ (Radulescu's Das Andere, 1984, for violin, viola or cello, accurately notates multiphonics on bowed strings).

In the 1990s, works by Michael Bach and Michael Liebman discussed the technique on cello and double bass but did not present concrete fingering charts. ${ }^{9}$ Pockets of compositional activity include Gerard Grisey, who notates, albeit with some mistakes, multiphonics for cello and viola in Vortex Temporum III (1994-96), Salvatore Sciarrino (early usage in Quarderno di Strada (2003) and extensive usage in the ninth string quartet (2012)), and Caspar Johannes Walter, as detailed in his article in this special issue. Knut Guettler and Håkon Thelin's contribution to the physical understanding of multiphonics and Caspar Johannes's mathematical concretisation constitute important building blocks in our understanding. ${ }^{10}$ Fingering charts for piano ${ }^{11}$, cello ${ }^{12}$ and guitar ${ }^{13}$ began the process of standardisation and, although some of this research has been independent, these charts fit together pleasingly well. This special issue is an attempt to prove the coherence of string multiphonics, show the current state of the art, and forge a joint path forward.

We begin with Caspar Johannes Walter's account of his discovery of multiphonics, initially as technical 'mistakes' existing within transitions between high harmonics and other sounds, and the eventual integration and development of this technique in his compositions.

${ }^{4}$ For flute sources see Robert Dick, The Other Flute (Oxford: Oxford University Press 1975) and Carin Levine and Christina Mitropoulos-Bott, The Techniques of Flute Playing (Kassel: Bärenreiter, 2002); for oboe see Peter Veale and Claus-Steffen Mahnkopf, The Techniques of Oboe Playing (Kassel: Bärenreiter, 1998) and Christopher Redgate, www.21stcenturyoboe.com; for clarinet see Nicholas del Grazia, www.clarinet-multiphonics.org; for saxophone see Marcus Weiss and Giorgio Netti, The Techniques of Saxophone Playing (Kassel: Bärenreiter, 2010); and for bassoon see Pascal Galois, The Techniques of Bassoon Playing (Kassel: Bärenreiter, 2010).

5 Heather Roche, https://heatherroche.net/category/multiphonic/ and Helen Bledsoe, https://helenbledsoe.com

${ }^{6}$ Håkon Thelin, Multiphonics on the Double Bass (PhD Thesis, Norwegian Academy of Music, 2011), available at http://haakonthelin.com/multiphonics/uploads/files/4\%20Multiphonics/ Multiphonics\%20on\%20the\%20Double\%20Bass.pdf.

7 John Schneider, The Contemporary Guitar (Berkeley: University of California Press, 1985).

8 Private e-mail correspondence with the author.

9 See Michael Bach, Fingerboards and Overtones (Munich: Edition Spangenberg, 1991) and Michael Liebman, 'Multiphonics: Neue Möglichkeiten in Cellospiel', Das Orchester 4/1 (2001).

${ }^{10}$ See Knut Guettler and Håkon Thelin, 'Bowed-String Multiphonics Analyzed by use of Impuls Response and the Poisson Summation Formula', Journal of the Acoustical Society of America, 131/1, pt. 2 (2012), pp. 766-72, and Caspar Johannes Walter, 'Mehrklänge auf dem Klavier: vom Phänomen zur mikrotonalen Theorie und Praxis', in Mikrotonalität - Praxis und Utopie, ed. Cordula Pätzold and Caspar Johannes Walter (Mainz: Schott, 2014), pp. 13-40.

11 Walter, 'Mehrklänge auf dem Klavier'.

12 Ellen Fallowfield, Cello Map (2013), www.cellomap.com/index/the-string/multiphonicsand-other-multiple-sounds.html.

${ }^{13}$ Seth F. Josel and Ming Tsao, The Techniques of Guitar Playing (Kassel: Bärenreiter, 2014). 
He also introduces his 'fraction windowing' algorithm, used to predict the components of multiphonics, and the online tools that he has developed for composers and performers. Seth Josel and Thomas Ciszak significantly expand upon existing multiphonic charts for the guitar - those by Josel himself and Ming Tsao for acoustic guitar by investigating multiphonics on all six strings of various models of electric guitar and providing fingering charts for the as-yet underresearched strings $1-3$. They compare results on five different guitars and detail the response of analogue effect pedals. Ellen Fallowfield compares existing fingering charts and suggests modifications and extensions to cello multiphonics, using audio analysis to point to certain areas of technical and musical interest, including pitch content, chainlike multiphonics, the balance and the intonation of components.

In contrast, there is a dearth of resources for harp multiphonics, so Gunnhildur Einarsdóttir considers the transition between 'extended harmonics' (any harmonic above the 2nd) and multiphonics in terms of technique and pitch content. She proposes three multiphonics, all of them technically realistic to locate because of their relative proximity to the $3 \mathrm{rd}$ harmonic. These could constitute a starting point for harpists. Sanae Yoshida considers multiphonics in the context of her research on microtonality in pianos. Then, focusing on timbre rather than pitch content, she expands the sound palette by suggesting playing techniques to colour multiphonics, including scordatura, pedalling techniques and glissandi.

Finally, Thomas Nicholson and Marc Sabat use Farey Sequences to determine a method for finding the location of 'playable nodes': the complete set of left-hand touching points to elicit respective harmonics. This theory can naturally be extended to multiphonics as a method of predicting their pitch content (or 'structure'). Furthermore, in the context of microtonality, Farey sequencing becomes a means of playing microtones reliably by pressing the string rather than touching it to produce microtonal intervals with inverse harmonic relations to the open string.

These articles have arisen from different approaches - theoretical, instrumental, analytical, compositional and performative - and different perspectives - microtonality, timbre, technique. Several themes recur, however, within these diverse texts: the pitch content of string multiphonics is, within certain limits, predictable and reliably reproducible, and the separation between harmonics and multiphonics is certainly not as clean-cut as the terminology would suggest. We hope that this special issue will stimulate further research. This will need to include timbre and intonation but, as always, the most important stimulus for future technical developments will be musical activity itself. 